\title{
Melting of multipass surface tracks in steel incorporating titanium carbide powders
}

\author{
S. Mridha ${ }^{1 *}$, A.N. Md Idriss ${ }^{2}$, M.A. Maleque ${ }^{3}$, I.I. Yaacob ${ }^{4}$ and T.N. Baker ${ }^{5}$ \\ ${ }^{1-4}$ Advanced Materials and Surface Engineering Research Unit \\ Department of Manufacturing and Materials Engineering, Kulliyyah of Engineering, \\ International Islamic University Malaysia, P.O. Box 10, 50728, Kuala Lumpur, Malaysia. \\ ${ }^{5}$ Department of Mechanical and Aerospace Engineering, University of Strathclyde \\ James Weir Building, Glasgow G1 1XJ, UK \\ Email: ${ }^{1 *}$ shahjahanmridha@gmail.com; ${ }^{2}$ ahmednazrin@gmail.com; ${ }^{3}$ maleque@iium.edu.my; \\ ${ }^{4}$ iskandar_yaacob@iium.edu.my; ${ }^{5}$ neville.baker@strath.ac.uk
}

1*: Corresponding author; Permanent address: 1 Yarrow Road, Glasgow G64 3NF, UK Phone: +44 (0) 1417728831

\begin{abstract}
Overlapping tracks were processed by melting preplaced titanium carbide (TiC) powder on steel surfaces using a tungsten inert gas torch. The tracks produced $\sim 1.0 \mathrm{~mm}$ melt depth free from cracks, but occasional pores were observed. The microstructure consisted of unmelted and partially melted $\mathrm{TiC}$ particulates together with reprecipitated $\mathrm{TiC}$ particles, which were prominent in tracks processed in the initial stage. A greater number of reprecipitated globular and cubic TiC particles were observed in tracks processed in the later stages, indicating more dissolution of TiC particulates from the overlapping operation. Those multitracks processed in the initial stage developed a maximum hardness of $850-1000 \mathrm{HV}$, which was lower in most other tracks, although comparable hardness values were recorded in the last track.
\end{abstract}


Keywords: Steel, Welding torch melting, Composite coating, Overlapping, Microstructure, Hardness

\section{INTRODUCTION}

The formation of a thin hard coating on substrate surfaces can improve tribological properties in terms of low friction and wear resistance, but if the load is high, the coating can fail by deformation of the subsurface, especially in light metal alloys. Reinforcement of metals with ceramics can increase strength, stiffness, wear resistance, high temperature strength and affect a decrease in weight. Over the years, modification of the matrix close to the surface, as well as reinforcement, has been introduced. The incorporation of ceramic particles into molten metal surfaces to produce metal matrix composite (MMC) layers is popular, because this method can tailor the surface to suite the requirements of specific applications. High energy laser and electron beam melting techniques are established means of processing such composite layers, which are reported to increase wear and corrosion resistance significantly. ${ }^{1-8}$ However, application of these techniques is limited in practice because of the high costs of the equipment. Previous surface engineering work using the tungsten inert gas (TIG) welding torch melting technique, ${ }^{9-19}$ produced either a small hemispherical volume of a modified surface, or a single melt track with a width of a few millimetres running the length of the specimen. However, in many service applications there is frequently a requirement to modify a much greater surface area. This necessitates the overlapping of many melted tracks, with the additional problems due to preheating of the regions of the substrate where subsequent tracks are melted, as reported for laser processing. ${ }^{20-23} \mathrm{Hu}$ and Baker ${ }^{22}$ defined 'preheat' as the heat developed from melting the initial track, which then diffused by conduction throughout the work piece. Previous laser studies described overlapping investigations based on a titanium alloy, initially involved laser nitriding ${ }^{22}$ and subsequently laser alloying which incorporated SiC powder. ${ }^{23}$ Although most of the work on MMC layer formation is centred on light metal 
alloys, ${ }^{8}$ there is interest in developing MMC layers on iron -based alloys for wear resistant applications. ${ }^{24-26}$ The term 'additive layer manufacturing' has recently been used to describe this process in the case of steels. ${ }^{27}$

$\mathrm{TiC}$ has received some attention as a reinforcing material on the substrate surface to increase resistance against wear. ${ }^{25}$ In parallel research with overlapped tracks, the TIG process was used to melt TiC powder on an AISI 1050 mild steel substrate. This achieved an approximately constant microhardness value of $800 \mathrm{HV}$ in the first track, from the surface to the depth at $2.2 \mathrm{~mm}$. The hardness in the third pass was in the range from 650 to $870 \mathrm{HV} .^{24}$ Earlier work on single track melting, incorporated $1.0 \mathrm{mg} / \mathrm{mm}^{2}$ of preplaced TiC powder into a low alloy steel surface. Using a TIG energy input of $1344 \mathrm{~J} \mathrm{~mm}^{-1}$, MMC layers having a good metallurgical bond and free from cracks and porosity were obtained. ${ }^{25}$ The microstructure consisted of $\mathrm{TiC}$ dendrites associated with unmelted and partially melted $\mathrm{TiC}$ particulates dispersed in the melt pool.

A review of the literature shows that little has been published relating microstructure to properties of overlapping tracks processed on a steel surface. This paper extends the work reported in a previous paper. ${ }^{26}$ It describes the influence of multipass overlapping tracks processed using TiC powder preplaced on AISI 4340 low alloy steel and melted under a TIG torch, but using a higher energy input, with the aim of dissolving particulates and precipitating more $\mathrm{TiC}$ in a finer form, with a homogeneous distribution. Research was undertaken to characterize the multipass overlapping features such as the melt geometry, microhardness and microstructure, including defects, of the processed tracks.

\section{EXPERIMENTAL}

AISI 4340 low alloy steel plate of composition given in Table 1 was used as the substrate material for this investigation. Specimens of $100 \times 40 \times 15 \mathrm{~mm}^{3}$ were cut from the steel plate. Four $3 \mathrm{~mm}$ dia. holes were drilled into the specimen in the positions shown in Fig. 1, to 
monitor temperature changes during the processing. The surface was ground on emery paper and degreased in acetone prior to the application of the preplaced powder. TiC ceramic powder of $99.5 \%$ purity, with a nominal size of $45-100 \mu \mathrm{m}$ supplied by Meterion Inc, USA was used as the reinforcing material for incorporation onto the steel surface. $1.0 \mathrm{mg}$ of $\mathrm{TiC}$ powder per $\mathrm{mm}^{2}$ area of steel specimen was preplaced on the surface. Details of the powder preplacement method were described previously. ${ }^{11,25}$ Multipass tracks, with 50\% overlapping between tracks, were melted on the TiC preplaced surface using a TIG welding torch generated by applying a current of $80 \mathrm{~A}$ at $35 \mathrm{~V}$. The specimen stage had a traversing speed of $1.0 \mathrm{~mm} / \mathrm{s}$. A $2.4 \mathrm{~mm}$ diameter thoriated tungsten rod was used as the nonconsumable electrode. The tungsten was direct current electrode negative (DCEN). Before the melting operation begun, the tip of the electrode was positioned $1.0 \mathrm{~mm}$ above the preplaced powder surface. The sample was shielded using argon gas flowing at $20 \mathrm{~L} \mathrm{~mm}^{-1}$, which was directly streamed into the melt pool to prevent excessive oxidation. A total of 17 multipass overlapping tracks were processed, with a time interval of about 2 minutes between every two tracks. The energy input $(H)$ for melting under the torch for the experimental conditions given above was $1344 \mathrm{~J} \mathrm{~mm}^{-1}$ calculated using Equation 1, where $V$ is voltage, $I$ is current, $S$ is scanning speed and $\eta$ is the efficiency of heat absorption, which is given as $48 \%$ for TIG torch melting. ${ }^{28}$ Analytical models for calculating $\eta$ are given in, for examples, References ${ }^{29}$ and ${ }^{30}$. For a rapidly moving high-power heat source, theoretically about $48 \%$ of the effective (net) heat input is available for fusion (in the $2 \mathrm{D}$ case). This value has been calculated by assuming that heat diffusion is exclusively perpendicular to the moving heat source and that no filler material is added. ${ }^{30}$ Experimental results agree with the calculated value. ${ }^{31-33}$

$$
H=\eta \frac{V I}{S}
$$


Table 1: Composition of AISI 4340 low alloy steel in wt.-\%

\begin{tabular}{ccccccccc}
\hline $\mathrm{C}$ & $\mathrm{Mn}$ & $\mathrm{Si}$ & $\mathrm{S}$ & $\mathrm{P}$ & $\mathrm{Cr}$ & $\mathrm{Ni}$ & $\mathrm{Mo}$ & $\mathrm{Fe}$ \\
\hline 0.40 & 0.57 & 0.30 & 0.04 & 0.035 & 1.15 & 2.57 & 0.63 & $\mathrm{Bal}$ \\
\hline
\end{tabular}

The microhardness was measured using a Wilson Wolpert Vickers tester with load of $500 \mathrm{~g}$ force, incorporating a $10 \mathrm{~s}$ delay, at different depths in the middle regions of the melt cross sections of each track. The error in hardness was $\pm 5 \%$. A Nikon measuring optical microscope type mm-400/L, a JEOL 5400 and a Hitachi S-3700N with an Oxford Instruments INCA system with 80mm XMAX SDD detector, scanning electron microscopes, operated in the range 7 to $20 \mathrm{kV}$, were used to analyse microstructures of the resolidified multipass tracks.

\section{RESULTS}

\subsection{Substrate Temperature Variations during Multi-track Processing}

Fig. 2 shows the variations in temperature recorded by the four thermocouples during processing. They were placed as follows: (T1), steel plate, (T2), track no.3, (T3), track no. 9 and (T4), track no.17. The temperature recorded by $\mathrm{T} 1$ at the end processing track 1 , was $71^{\circ} \mathrm{C}$. As melting proceeded, T1 recorded temperatures between tracks 2 and 15 of $100 \pm$ $10^{\circ} \mathrm{C}$. Due to the preheat, the corresponding temperatures recorded by $\mathrm{T} 2$ started at $128^{\circ} \mathrm{C}$, reached $167^{\circ} \mathrm{C}$, at track 5 and stayed above $140^{\circ} \mathrm{C}$ until track 14 . The highest range of temperatures was recorded by $\mathrm{T} 3$, being over $207^{\circ} \mathrm{C}$ from track 6 until track 15 . Due to the cooling effect of metal beyond the last track, the temperatures recorded by T4 were generally lower than those of $\mathrm{T} 2$. A maximum temperature of $238^{\circ} \mathrm{C}$ was recorded by $\mathrm{T} 3$.

\subsection{Melt Pool Geometry and Defects}

The cross sections of all 17 multipass tracks, spanning across $\sim 35 \mathrm{~mm}$ width of the substrate, were examined by optical and scanning electron microscopy. The vertical cross sections of 
the processed specimens had hemispherical shaped individual track seen within the overall resolidified melt layer, which were followed by a distinct heat affected zone (HAZ), Fig. 3. The tracks showed a good metallurgical bonding with the substrate, were free from cracks, but pores were visible in some tracks. The measured melt depths of the multipass overlapping tracks in Table 2 clearly show that the average melt depth is $\sim 1.0 \mathrm{~mm}$.

Table 2: Size of melt pool and HAZ.

\begin{tabular}{cccccccccccccccccc}
\hline $\begin{array}{c}\text { Track } \\
\text { No. }\end{array}$ & 1 & 2 & 3 & 4 & 5 & 6 & 7 & 8 & 9 & 10 & 11 & 12 & 13 & 14 & 15 & 16 & 17 \\
\hline $\begin{array}{c}\text { Depth, } \\
\text { mm }\end{array}$ & 1.0 & 1.0 & 1.0 & 0.9 & 1.1 & 0.9 & 1.1 & 1.0 & 1.0 & 1.0 & 1.0 & 1.2 & 1.1 & 0.8 & 1.1 & 0.8 & 1.1 \\
\hline $\begin{array}{c}\text { HAZ, } \\
\text { mm }\end{array}$ & 1.4 & 1.2 & 1.2 & 1.5 & 1.4 & 1.5 & 1.4 & 1.5 & 1.6 & 1.6 & 1.3 & 1.2 & 1.4 & 1.7 & 1.2 & 1.4 & 1.3 \\
\hline
\end{tabular}

The powder-covered area exposed for melting in the first track was a circular area across the width of the TIG torch scanned along the traverse direction. Due to the overlapping procedure, after processing the first and the final tracks, the torch remelted $50 \%$ of these tracks together with $50 \%$ of new substrate.

\subsection{Hardness of TiC Embedded Alloy Steel}

Fig. 4 shows the hardness profiles along the melt depths of some selected overlapping tracks to cover the start, nos. 1-2, the middle, nos. 9-10 and the final track processed, no.17. The results show variations in hardness values, from the steel matrix of $\sim 300 \mathrm{HV}$. The hardness developed a maximum value of $1000 \mathrm{HV}$ in track 1 , while in tracks $1-2$, a hardness value $>750 \mathrm{HV}$ was retained to a depth of about $1.0 \mathrm{~mm}$, which then reduced rapidly to around 420 HV. On the other hand, tracks 9-10 only reached a maximum hardness of 650-700 HV. Track 17 , which only had by $50 \%$ of the width remelted, would cool much faster than the previous tracks, and recorded hardness values similar to tracks 1 and 2. Also, in the HAZ of track 17, the hardness values of $\sim 600 \mathrm{HV}$ were retained to a depth of $\sim 2 \mathrm{~mm}$, a significantly higher figure than $\sim 450 \mathrm{HV}$, found for the other tracks. 


\subsection{Microstructure of TiC Embedded Composite Layer}

The main features of each track were a hemispherical resolidified melt pool, with embedded TiC particles, and an associated HAZ, Fig. 3. In this work, TiC powder particles, which remain unmelted or partially melted are described as $\mathrm{TiC}$ particulates, while $\mathrm{TiC}$ powders which have completely melted and formed as new particles, are described as precipitates.

Thermal shock, due to the high heat input and high cooling rates following the TIG melting, resulted in some TiC particulates cracking, allowing liquid matrix to infiltrate, filling the gaps, Fig. 5. Agglomeration of TiC particulates was seen in areas near to the track edges and at the melt front, Fig. 6a. Another feature in Fig. 6a, and at a higher magnification in Fig. 6b, is the presence, throughout the melt zone, of the early stages of dendrite formation.

The initial half of the first track, which had not been remelted, consisted of unmelted particulates ( $\geq 45 \mu \mathrm{m}$ with sharp edges) and partially melted TiC particulates (rounded edges) together with a variety of precipitates in the size range $\sim 5-10 \mu \mathrm{m}$. Examples are seen in Fig. 7 . The precipitates are significantly smaller than the preplaced 45-100 $\mu \mathrm{m}$ TiC powder. This kind of microstructure was also reported in previous work on the composite coatings produced by the single track melting technique. ${ }^{24,25}$ More precipitated TiC particles were observed in the upper region of the track, Fig. 8. This can be attributed to the dissolution of TiC particulates being greater near to the torch source, so that the high temperature fluid took a longer time to solidify, resulting in a high volume of $\mathrm{TiC}$ precipitation.

Compared to the first track, precipitation of TiC particles was more evident in the second track, where the microstructure also contained undissolved TiC particulates in the upper region. Since the second overlapping track remelted a fraction of the first track, together with a smaller volume of the preplaced powder, the microstructure shown in Fig. 8 contains mostly globular and cubic type TiC particles. Compared to the first track, these are precipitated over a longer solidification time of the liquid, which contains more dissolved TiC particulates. The 
microstructure in Fig. 9 clearly shows the phenomenon of TiC particulate dissolution and precipitation. The dissolution process started at the particulate surface with the simultaneous nucleation and precipitation of globular $\mathrm{TiC}$ around the melting particulate. The precipitation of cubic and dendritic TiC particles occurred more frequently in areas some distance from the dissolving particulate.

While few, and in some areas, no unmelted or partially melted particulates were found in the ninth melted track, all the above noted morphologies of precipitated TiC particles were observed. These included cruciform or flower shaped $\mathrm{TiC}$ precipitates, observed at $\mathrm{C}$ in Fig. 10, at the middle of the track, and in more detail in Fig. 11.

Heat dissipation by conduction through the substrate -mass produced a martensitic microstructure within the HAZ of all overlapping tracks, Fig. 12.

\section{DISCUSSION}

The approach underpinning the development of a thick (>1 mm), hard, wear resistant MMC layer on an alloy substrate in this research, was that by using a surface engineering process, initially based on a laser and more recently on a TIG torch, hard ceramic powders could be incorporated into a molten substrate. Invariably, the ceramic powders have a much higher melting point $\left(\sim 2,500-3500^{\circ} \mathrm{C}\right)$ than the alloy substrate $\left(650-1600^{\circ} \mathrm{C}\right)$, and the early laser processing work of Ayres ${ }^{1,2}$ incorporating $\sim 150 \mu \mathrm{m}$ size TiC, WC or diamond particles into a titanium substrate, indicated an inhomogeneous distribution of the powder. However, with laser processing preplaced $\mathrm{SiC}$ powder in the size range, 3-6 $\mu \mathrm{m}$, on a Ti-4Al-6V alloy substrate ${ }^{4}$ the powder dissolved and precipitated as well distributed $\mathrm{TiC}$ and $\mathrm{Ti}_{5} \mathrm{Si}_{3}$ particles, conferring a significant increase in hardness throughout a $\sim 1 \mathrm{~mm}$ deep solidified melt pool. In the present work, this methodology is applied to TIG torch processing preplaced TiC powder on an alloy steel surface. Unlike the $\mathrm{Fe}-\mathrm{Si}-\mathrm{C}$ system, ${ }^{34} \mathrm{Fe}$ does not dissolve in $\mathrm{TiC},{ }^{35}$ 
therefore the resultant particle distribution should reflect this difference. Also this research was extended to a situation where multi-overlapping tracks cover the substrate.

However, the results collated in Table 2 do not follow the trend reported in previous work. ${ }^{36}$ Here the track depth remained almost constant for the length of the track, at $\sim 1 \mathrm{~mm}$, as seen in Fig. 3 and recorded in Table 2. It is considered that the influence of preheating due to the overlapping operation depends both on the energy input and the time interval between two overlapping tracks being sufficiently short. In these experiments, a longer time interval of $\sim 2$ minutes was used than in previous work. ${ }^{22,36}$ For these reasons, the melt depth is evidently not showing the previously recorded extensive preheating effect of increasing track depth as melting proceeds. ${ }^{21,22}$

Few pores were noted in this work. Their formation is associated with the rapid solidification of the melt, entrapping gases which may arise from the shielding gas and also through burning off the binder used for adhering the TiC powder on to the substrate surface. ${ }^{4,11,19}$ Pores have been reported when other melting techniques were used for surface modification work. ${ }^{3,4,25}$ For example, it has been observed that with the laser cladding process, the powder that is excess to that injected into the melt pool during overlapping, may produce inter-track porosity. ${ }^{37}$

The maximum hardness of $1000 \mathrm{HV}$ was observed only for the first track, where it was $\sim 3.5$ higher than the substrate material hardness of 300 HV. Fig. 4 shows that this maximum hardness was retained for $\sim 500 \mu \mathrm{m}$. Following the melting of the second track, a high hardness plateau of $870-750 \mathrm{HV}$ was recorded to a depth of $\sim 1 \mathrm{~mm}$. It is noted in Fig. 3, that the overlapping between tracks 1 and 2 is significantly less than the aim-at $50 \%$, and this has influenced the variations in hardness between these two tracks. Within the HAZ, the hardness values, ranging from 300-470 HV, resulted from the martensitic microstructures developed 
due to the high cooling rates. However, these were not so high as to create residual stress levels capable of producing cracks in the solidified structures.

The effect of preheat recorded as a temperature increase from start to finish of the melting of a single track, or as a result of overlapping during the melting of a number of tracks, ${ }^{22,23,36}$ is well established, leading to a reduction in hardness after the initial track, in multi-track surface alloys. In the present work, a return to a higher hardness of $880 \mathrm{HV}$ in track 17, was recorded. This may be related to less dissolution of TiC particulates, because no remelting occurred in second half of this final track. The highest hardness recorded in the overlapping tracks is lower than the maximum hardness of 900-1200 HV reported previously in TiC incorporated composite coatings in steel, processed by single track melting. ${ }^{8,18}$ This decrease in hardness is related both to the high energy input used in this work and to the effect of preheat generated by the overlapping process, decreasing the cooling rate and modifying the microstructure.

Cracking of TiC particulates due to thermal shock, observed in Fig. 5, allowed the infiltration of molten steel between the shattered particulates, resulting in acceleration of dissolution of the cracked particulates in the presence of a Marangoni convection force, compared to the dissolution of uncracked TiC particulates. The Marangoni convection force is reported to swirl the fluid melt near the arc source, prior to moving this fluid into the deeper part of melt pool. This is an action which increases the rate of dissolution of reinforcing material, together with that the substrate. ${ }^{25}$ The low energy region at the bottom of the melt pool, adjacent to the base metal, where the pool was only just above the melting temperature of steel, was insufficient to melt the surging particulates, resulting in agglomeration, as seen in Fig. 6a. Because the Gaussian energy distribution of the melting torch steadily decreased from the melt pool centre towards the edges, the number of agglomerations of $\mathrm{TiC}$ particulates increased, together with a reduced population of precipitated particles. This is 
observed in the microstructure in Fig. 7. During melting of the first track, more powder was introduced into the melt pool, producing a viscous melt of relative low fluidity, which solidified in a shorter time. This explains why the resolidified melt pool of the first track, seen in Figs. 5 and 7, retained a greater number of unmelted and partially melted TiC particulates. Depending on the melt temperature, the Maragoni forces and the solidification time at localized positions, preferential dissolution of some particulates and precipitation may continue until the particulate dissociated completely, being replaced by globular precipitated particles.

The higher hardness in tracks 1 and 2 is related to the presence of well distributed TiC precipitates, compared to other overlapping tracks. However, the Maragoni forces displaced many of the TiC particulates to a zone at the bottom of the melt pool, Figs. 6a and 7, where they have no influence on the surface wear resistance. The overlapping process remelted $50 \%$ of the resolidified track and preheated the substrate, thereby reducing the cooling rate, all of which contributed to reducing the surface hardness. This phenomenon of ceramic particulate dissolution and precipitation was also observed in the earlier research work. ${ }^{7,8,38}$ Wang et al., ${ }^{16}$ in their multi-pass overlapping experiments, which involved synthesizing a mixture of FeTi and graphite onto a medium carbon steel using the TIG process, unlike the present work, observed a greater concentration of TiC particles in the upper region. Here, they found many large precipitates, $>50 \mu \mathrm{m}$, and included in the paper some excellent electron probe X-ray micro-analytical images supporting the presence of only titanium and carbon in the dendritic and cruciform precipitates. These are similar to the cruciform (Ti, V) nitrides characterised by Baker et al., ${ }^{38}$ which they observed in thin slab cast vanadium-titanium microalloyed steels, and the faceted TiC six armed dendrites of Chen and Yang. ${ }^{39}$ On the other hand, Fernandez et al. $^{40}$ found that the equilibrium growth morphology of TiC is octahedral. Wang et al. ${ }^{16}$ concluded that the low density of $\mathrm{TiC}, \sim 4.90 \mathrm{~g} / \mathrm{cm}^{3}$, compared with iron, $\sim 8.9 \mathrm{~g} / \mathrm{cm}^{3}$, had a tendency to segregate in the upper region. However, it should be noted that compared with the 
energy input $422 \mathrm{~J} \mathrm{~mm}^{-1}$ used in previous research ${ }^{26}$ and $1344 \mathrm{~J} \mathrm{~mm}^{-1}$ in the present work, their energy input was $2550 \mathrm{~J} \mathrm{~mm}^{-1}$. Their precipitates, which were significantly larger than those seen in Fig. 11, while strengthening the steel, did not produce hardness values in all tracks of $\sim 1000 \mathrm{HV}$, reported by others for this TiC -steel system.

Preheating of the substrate to a temperature of $200^{\circ} \mathrm{C}$ was also reported to increase the track width together with developing a deeper melt, resulting in a greater dilution. However, significantly higher temperatures have been reported due to overlapping operation which caused preheating of the substrate to increase to $\sim 750{ }^{\circ} \mathrm{C} .{ }^{37}$ In the present work, the energy input would produce a high melt temperature and vigorous particulate-matrix stirring within the melt pool, resulting in the displacement of preplaced powder particulate to the bottom of the melt pool in the early tracks, as seen in Fig. 6. By the time the $9^{\text {th }}$ overlapping track was reached, the combination of the high heat input plus the level of the preheat, produced a melt temperature where most of the $\mathrm{TiC}$ particulates dissolved within the melt pool. This possibly accelerated the dissolution of $\mathrm{TiC}$ particulates at a faster rate than in the tracks processed in the earlier stage, especially in the first and second tracks.

During melting, the torch energy level of $1334 \mathrm{Jmm}^{-1}$ produced a situation which leads to the displacement, by Maragoni forces, of the TiC particulates preplaced on the substrate surface, to the bottom of the melt zone. As melting proceeded, the preheat increased, dissolving more and more particulates at an early stage, and $\mathrm{TiC}$ precipitation occurred on cooling. As the number of tracks melted increased, the rate of cooling decreased due to the increasing effect of the preheat. This resulted in a longer time for precipitate growth. A wide variety of precipitate morphologies were found, culminating in the six -sided 'flower' shaped precipitates, which are associated with a relatively slow cooling rate. The growth of these precipitates and their inhomogeneous distribution was accompanied by a decrease in the hardness throughout the melt zone, as the multi-track processing continued, until the last 
track, which was only half remelted, and therefore cooled faster than most of the preceding tracks. The generally accepted particle radius for controlling grain size ${ }^{41}$ is in the range 30 $800 \mathrm{~nm}$, together with a volume fraction of $10^{-4}$ to $10^{-2}$. The flower precipitates removed a significant fraction of the available $\mathrm{Ti}$ and $\mathrm{C}$ atoms, which are effectively lost in a precipitate which is outside this size range, and therefore wasted in terms of controlling the strength properties, through either dispersion hardening or by restriction of grain growth. It is considered that in multi - track melting, a decrease in the energy input to $<1000 \mathrm{Jmm}^{-1}$, may reduce the Marangoni flow, through a change in surface tension. ${ }^{42}$ This, in turn, should develop a microstructure with a more homogeneous distribution of $\mathrm{TiC}$ particulates and precipitates with a corresponding effect on hardness. It is expected that a higher hardness, homogeneously distributed throughout the re-solidified melt zone, would also benefit the triobological properties.

\section{CONCLUSIONS}

Crack- free composite coated overlapping tracks of an average melt depth of $1.0 \mathrm{~mm}$ and HAZ depth of $1.4 \mathrm{~mm}$, have been successfully produced by incorporating a $1.0 \mathrm{mg} / \mathrm{mm}^{2}$ preplaced TiC powder layer on AISI 4340 steel surface, using a TIG torch heat source of 1344 $\mathrm{J} \mathrm{mm}^{-1}$ energy input. Microstructures of the first track revealed more TiC particulates than the other subsequent tracks, because the $1^{\text {st }}$ half of this track was not affected by the overlapping melting operation. The multipass overlapping tracks remelted the undissolved and partially dissolved TiC particulates embedded in the adjacent layer, producing a greater subsequent precipitation of $\mathrm{TiC}$ of cubic, globular and dendritic morphologies. The increased dissolution of $\mathrm{TiC}$ particulates due to remelting, and also preheating associated with the overlapping process, produced mostly dispersed reprecipitated $\mathrm{TiC}$ in the melt microstructure. The first track, containing more unmelted and partially melted TiC particulates, developed a maximum hardness of $1000 \mathrm{HV}$. This hardness value reduced significantly when more TiC particulates 
were dissolved in subsequent tracks. The dense population of different morphologies of TiC precipitates in the earlier overlapping tracks contributed to high hardness. It was found that the overall hardness developed in the multipass tracks was 2.5-3.5 times that of the steel substrate hardness of $300 \mathrm{HV}$. The HAZ consisted of martensitic microstructure with a hardness of 300-600 HV.

The results of this investigation confirm that conventional TIG technology may be used as an alternative to the more expensive laser process to produce composite coatings on surface engineered steels. Processing procedures are currently being explored to address the problem of microstructural and hardness variations reported in this research.

\section{ACKNOWLEDGEMENT}

The authors would like to thank the Research Management Centre Of International Islamic University Malaysia for monetary assistantship under the Grant RCG-U34-10-001-0002.

\section{REFERENCES}

[1] J.D. Ayers, R. T. Schaffer, W. P. Robey: 'A laser processing technique for improving the wear-resistance of metals', J. Metal, 1981, 33, 19-23.

[2] J.D. Ayers, R.N. Bolster: 'Abrasive wear with fine diamond particles of carbidecontaining aluminum and titanium alloy surfaces', Wear, 1984, 93, 193-205.

[3] J.H. Abboud, D.R.F. West: Microstructure of titanium injected with SiC particles by laser processing', Mater. Sci. Lett., 1991, 10, 1149-1152.

[4] S. Mridha, T.N. Baker: 'Incorporation of $3 \mu \mathrm{m} \mathrm{SiCp}$ into Titanium surfaces using a 2.8 $\mathrm{kW}$ laser beam of 186 and $373 \mathrm{MJm}^{-2}$ energy densities in a nitrogen environment', $J$. Mater. Process. Technol., 2007, 185, 38-45.

[5] M.J. Chao, W.L. Wang, E.J. Liang, D. Ouyang: 'Microstructure and wear resistance of TaC reinforced Ni-based coating by laser cladding', Surf. Coat. Technol., 2008, 202, 1918-1922.

[6] X.H. Wang, M. Zhang, X.M. Liu, S.Y. Qu, Z.D. Zou: 'Microstructure and wear properties of TiC/FeCrBSi surface composite coating prepared by laser cladding', Surf. Coat. Technol., 208, 202(15), 3600-3606.

[7] H.-g.L. Kai-jin Huang, Zhou Chang-rong: 'Laser Cladding of $\mathrm{Zr}_{55} \mathrm{Al}_{10} \mathrm{Ni}_{5} \mathrm{Cu}_{30} / \mathrm{SiC}$ Amorphous Composite Coatings on AZ91D Magnesium Alloy for Improvement of Corrosion Resistance', Adv. Mat. Res., 2011, 179-180, 757-761 
[8] T.N. Baker, in: H. Dong (Ed.), Surface Engineering of Light Alloys - Aluminium, Magnesium and Titanium Alloys, Wood Publishing Ltd, Oxford, 2010, pp 398-443.

[9] S. Atamert, H. K. D. H. Bhadeshia: 'Comparison of the microstructures and adhesive wear properties of stellite hardfacing alloys deposited by arc welding and laser cladding', Metall. Trans. A, 1989, 20A, 1037-1054.

[10] T.I. Kahn, D. Fowles: 'Surface modification of ti-6ai-4v alloy using metal arc heat source', Surf. Eng., 1997, 13, 257-259.

[11] S. Mridha, B.S. Ng: 'Addition of ceramic particles to GTAW melted titanium surfaces', Surf. Eng., 1999, 15(3), 210-215.

[12] S. Buytoz, M. Ulutan, M.M. Yildirim: 'Dry sliding wear behavior of GTAW welding clad WC composite coatings', Appl. Surf. Sci., 2005, 252, 1313-1323.

[13] S. Mridha: 'Titanium nitride layer formation by TIG surface melting in reactive environment', J. Mater. Process. Technol., 2005, 168, 471-477.

[14] D. Wenbin, J. Haiyan, Z. Xiaoqin, L. Dehui, Y. Shoushan: 'Microstructure and mechanical properties of GTA surface modified composite layer on magnesium alloy AZ31 with SiCP', J. Alloys Compd., 2007, 429, 233-241.

[15] X.H. Wang, S.L. Song, Z.D. Zou, S.Y. Qu: 'Fabricating TiC particles reinforced Febased composite coatings produced by GTAW multi-layers melting process', Mater. Sc. Eng. A, 2006, 441, 60-67.

[16] X.H. Wang, S.L. Song, S.Y. Qu, Z.D. Zou: 'Characterization of in situ synthesized TiC particle reinforced Fe-based composite coatings produced by multi-pass overlapping GTAW melting process', Surf. Coat. Technol., 2007, 201, 5899-5905.

[17] J. Liu, J. Huang, J. Liu, G. Song: 'Microstructure and Wear Resistance of TiC+Cr7C3 Reinforced Ceramal Composite Coating Produced by PTA Weld-Surfacing Process', Adv. Mat. Res., 2010, 97-101, 1377-1380.

[18] L.M. Wang, J.B. Liu, C. Yuan: 'Fe-Cr-C-TiC High-Chromium Fe-Based Ceramic Composite Coating Prepared by PTA Weld-Surfacing Process', Mater. Sci. Forum, 2011, 675-677, 783-787.

[19] S. Mridha, S. Dyuti: 'Formation of TiN Dispersed Composite Layer on Steel Surfaces by Titanium Powder Preplacement and TIG Surface Melting Processes', Adv. Mat. Res., 2011, 264-265, 1415-1420.

[20] K.P. Cooper and P. Slebodnick: 'Recent developments in laser melt/particle injection processing', J. Laser Appl., 1989, 1, 21-29.

[21] P.H. Morton, T. Bell, A. Weisheit, J. Kroll, B.L. Mordike, in: T.S. Sudarshan, J.F. Braza (Eds.), Surface Modification Technologies V, London, Institute of Materials, 1992, pp. 593-609.

[22] C. Hu, T.N. Baker: 'The importance of preheat before laser nitriding a Ti-6Al-4V alloy', Mater. Sc. Eng. A, 1999, 265, 268-275.

[23] T.N. Baker, M.S. Selamat: 'Surface engineering of Ti-6Al-4V by nitriding and powder alloying using a CW CO2 laser', Mater. Sci. Technol., 2008, 24, 189-200.

[24] Y.C. Lin, K.Y. Chang: 'Elucidating the microstructure and wear behavior of tungsten carbide multi-pass cladding on AISI 1050 steel', J. Mat. Proc. Tech., 2010, 210, 219225. 
[25] S. Mridha, A.N. Md Idriss, T.N. Baker: 'Incorporation of TiC particles on AISI 4340 low alloy steel surfaces via tungsten inert gas arc melting', Adv. Mat. Res., 2012, 445, 665-660.

[26] S. Mridha, T.N. Baker: 'Overlapping tracks processed by TIG melting TiC preplaced powder on low alloy steel surfaces', Mat. Sci. Technol., (2014), DOI 10.1179/1743284714Y.0000000530

[27] J. Hunt, F. Derguti, I. Todd: 'Selection of steels suitable for additive layer manufacturing', Ironmaking Steelmaking, 2014, 41, 254-256.

[28] K.E. Easterling: Introduction to Physical Metallurgy of Welding, ButterworthHeinemann, London (1992).

[29] N. Rykalin: Berechnung Der Wärmevorgänge Beim Schweissen, VEB Verlag Technik, Berlin (1957).

[30] D. Radaj: Heat Effects of Welding, Springer-Verlag (1992).

[31] P.W. Fuerschbach, G.A. Knorovsky: 'A Study of Melting Efficiency in Plasma Arc and Gas Tungsten Arc Welding', Weld. J., Res. Suppl., Nov 1991, 287s- 297s.

[32] J.N. DuPont, A.R. Marder: 'Thermal Efficiency of Arc Welding Processes', Weld. J., Res. Suppl., Dec 1995, 406s-416s.

[33] A.A. Wells: 'Heat flow in welding', Weld. J., May 1952, pp. 263s-267s.

[34] B.S. Terry, O.S.Chinyamakobvu: 'Assessment of the reaction of SiC powders with ironbased alloys', J. Mater.Sci., 1993, 28, 6779-6784.

[35] V. Raghavan: 'C-Fe-Ti(Carbon-iron-titanium)', J. Phase Equilibria, 2003, 24, 62-66.

[36] P. Patel, S. Mridha, T. N. Baker: 'Influence of shielding gases on preheat produced in surface coatings incorporating SiC particulates into microalloy steel using TIG technique', Mat. Sci. Technol., 2014, 30(12), 1506-1513.

[37] M. Schneider, Laser cladding with powder. Twente University, (Netherlands), Dissertation, 1998.

[38] T.N. Baker, Y. Li, J.A. Wilson, A. J. Craven, D. N. Crowther: 'Evolution of precipitates, in particular cruciform and cuboid particles, during simulated direct charging of thin slab cast vanadium microalloyed steels', Mat. Sci. Technol., 2004, 20, 720-730.

[39] Y. Chen, H.M.Yang: 'Growth morphology and mechanism of primary TiC carbide in laser clad TiC/FeAl composite coating', Mater. Lett., 2003, 57,1233-1238.

[40] R. Fernandez, J.C. Lecomte, T.E. Kattamis: 'Effect of solidification parameters on growth geometry of MC carbide in IN-100dendritic mono-crystals', Metall. Trans., 1978, 9A, 1381-1386.

[41] P. A. Manohar, M. Ferry and T. Chandra: 'Prediction of critical grain radius in particlecontaining materials', ISIJ International, 38 (1998), 913-. 924.

[42] K.C. Mills, B.J. Keene, R.F. Brooks and A. Shirali: 'Marangoni effects in welding' Phil.Trans. R. Soc. London. A, 356/1739 (1998), 911- 925. 


\section{List of Figures}

Fig. 1: Schematic diagram giving the position of the multitracks and thermocouple holes.

Fig. 2: Graph of temperature variation recorded by thermocouples during multitrack processing

Fig. 3: Cross section of some overlapping tracks showing melt layers and heat affected zone.

Fig. 4: Hardness profile of selected track in the multipass layers of TiC composite coating.

Fig. 5: Uncracked particulate (left) and matrix infiltration into the cracked TiC particulates (right)

Fig. 6: (a) TiC segregation and agglomeration of particulates in the second half of the track 17 between $\mathrm{X}$ and $\mathrm{Y}$ at the bottom of the melt zone; (b) quasi-dendrites of $\mathrm{TiC}$ enlarged from the box in Fig. 6a.

Fig 7: Sharp edged TiC particulate, with some rounded partially melted $\mathrm{TiC}$ and precipitation of $\mathrm{TiC}$ in the first track.

Fig. 8: TiC precipitates near the surface of the second track.

Fig. 9: Partial dissolution of two TiC particulates, A and B, with globular C, and angular D, precipitates within the third overlapping track.

Fig. 10: Flower precipitates are growing at $\mathrm{C}$ in the middle of the ninth melt track.

Fig. 11: SEM micrograph showing a well-developed TiC flower precipitate (f).

Fig. 12: Martensitic microstructure in the HAZ of the overlapping track. 


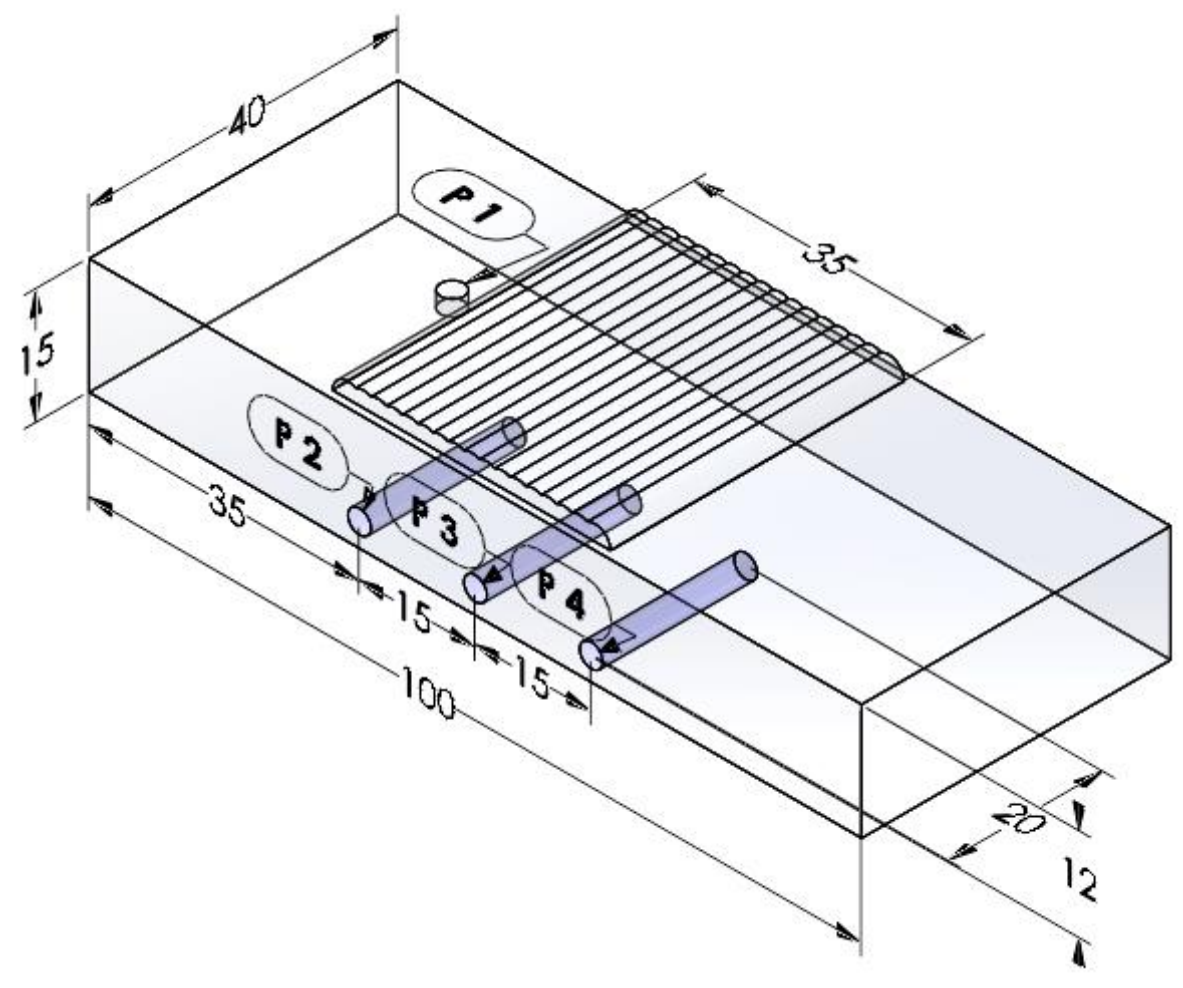

Fig. 1: Schematic diagram giving the position of the multi-tracks and thermocouple holes. 


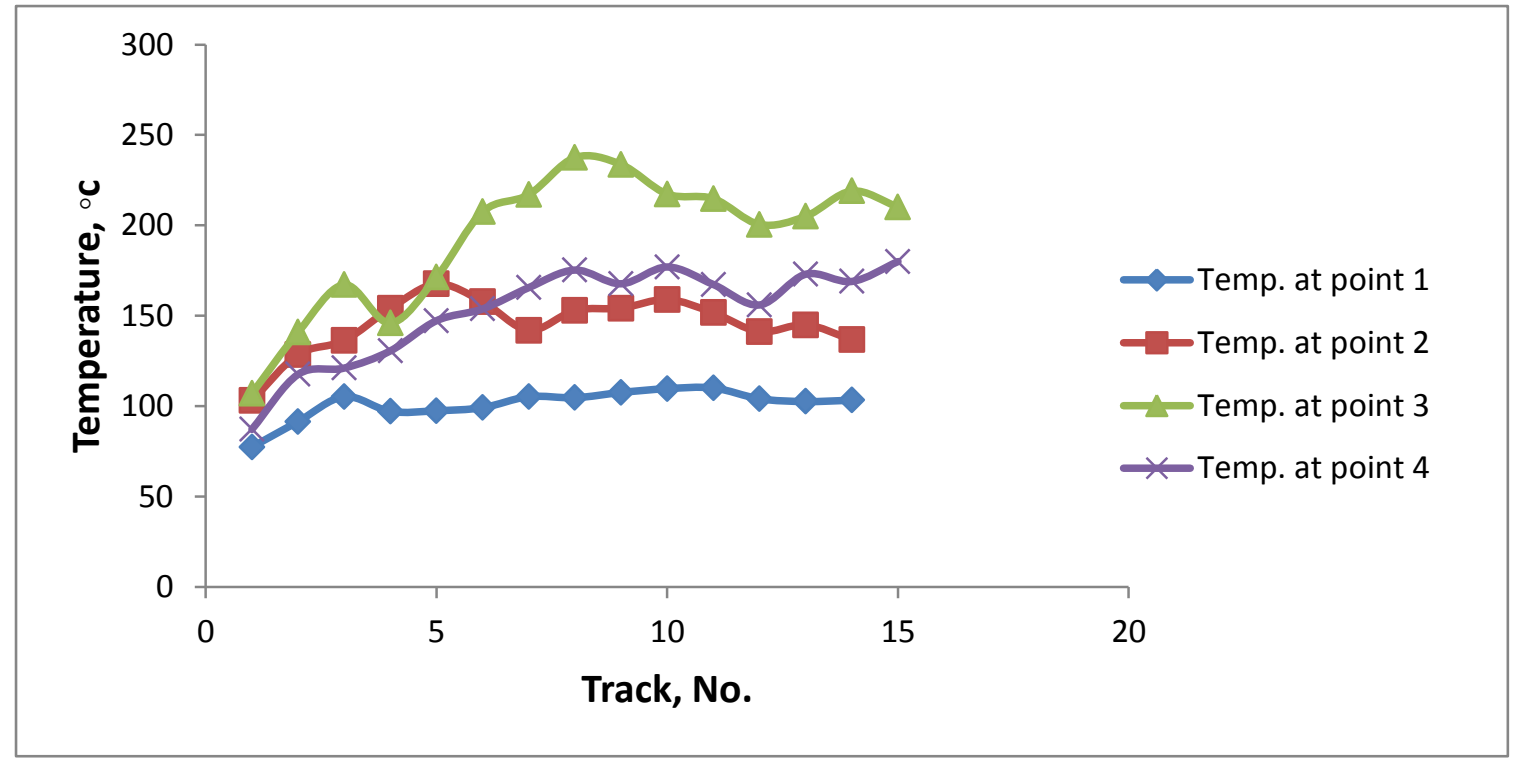

Fig. 2: Graph of temperature variation recorded by thermocouples during multitrack processing. 


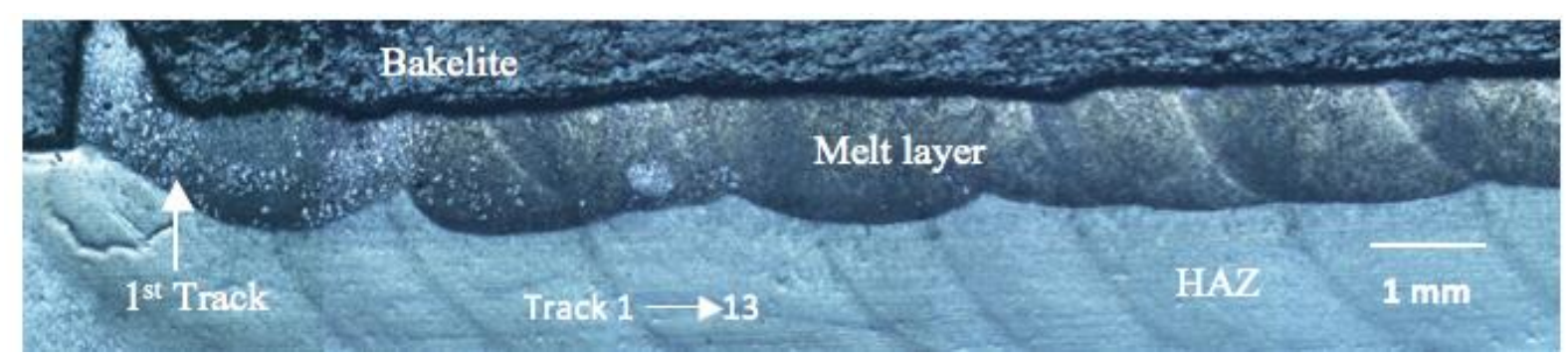

Fig. 3: Cross section of some overlapping tracks showing melt layers and heat affected zone. 


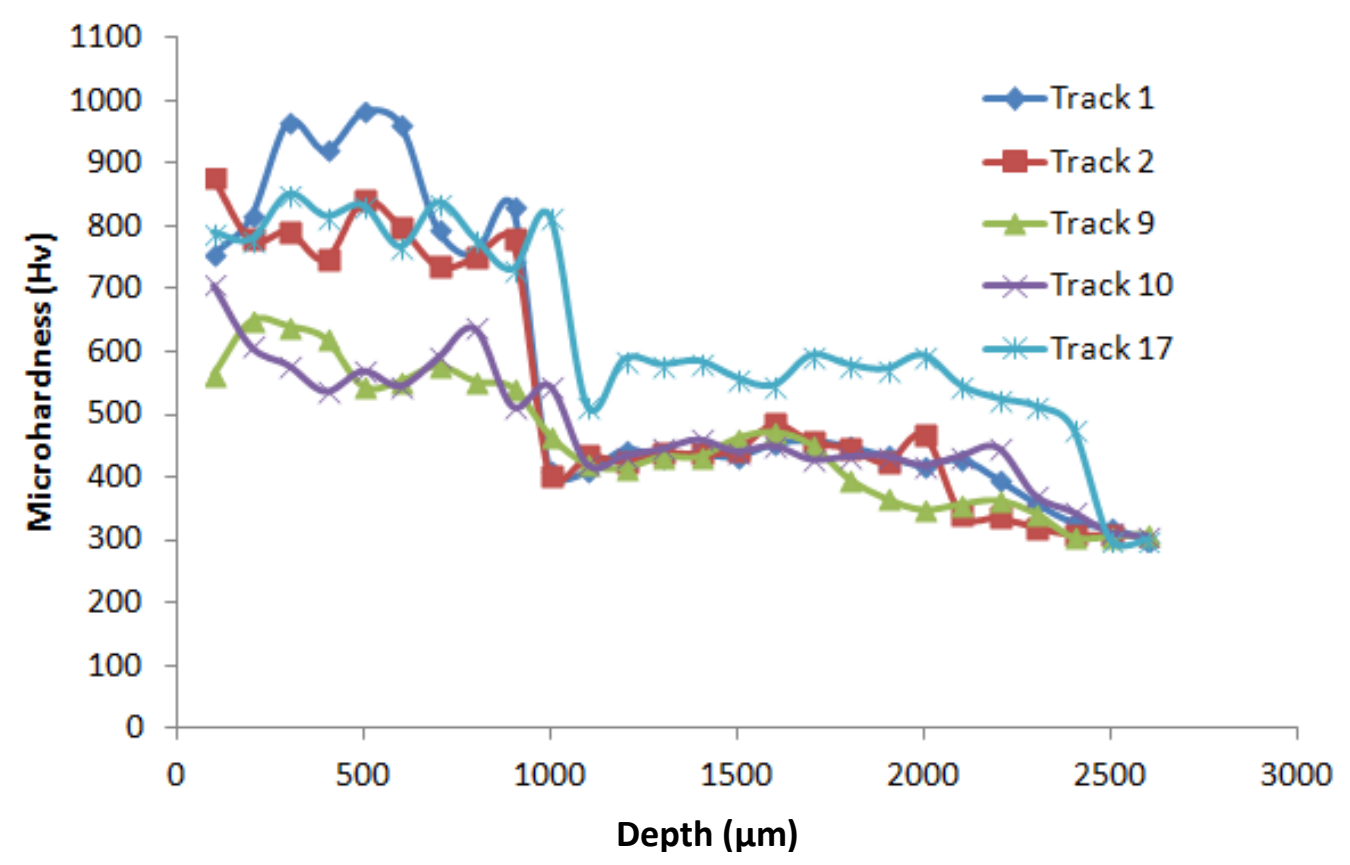

Fig. 4: Hardness profile of selected tracks in the multipass layers of $\mathrm{TiC}$ composite coating. 


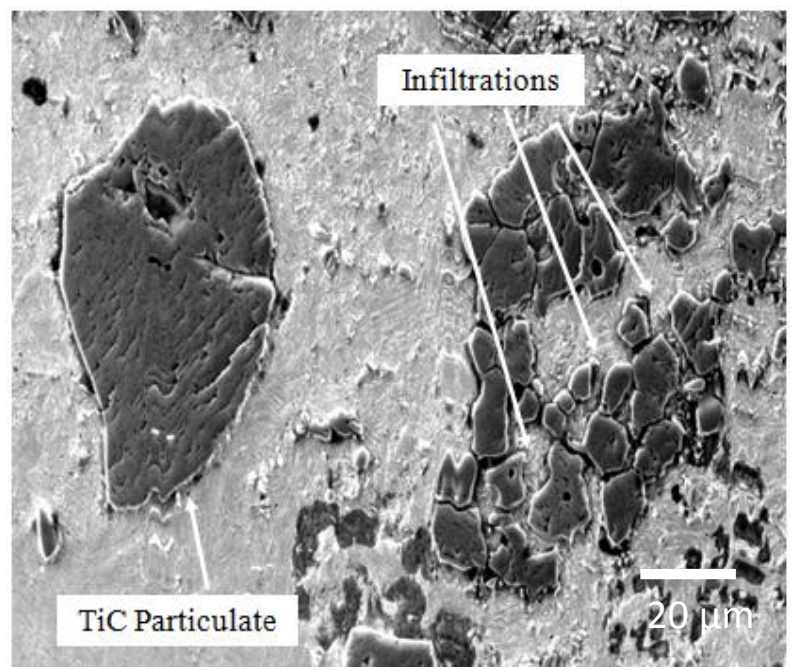

Fig. 5: Uncracked particulate (left) and matrix infiltration into the cracked-TiC particulates (right). 

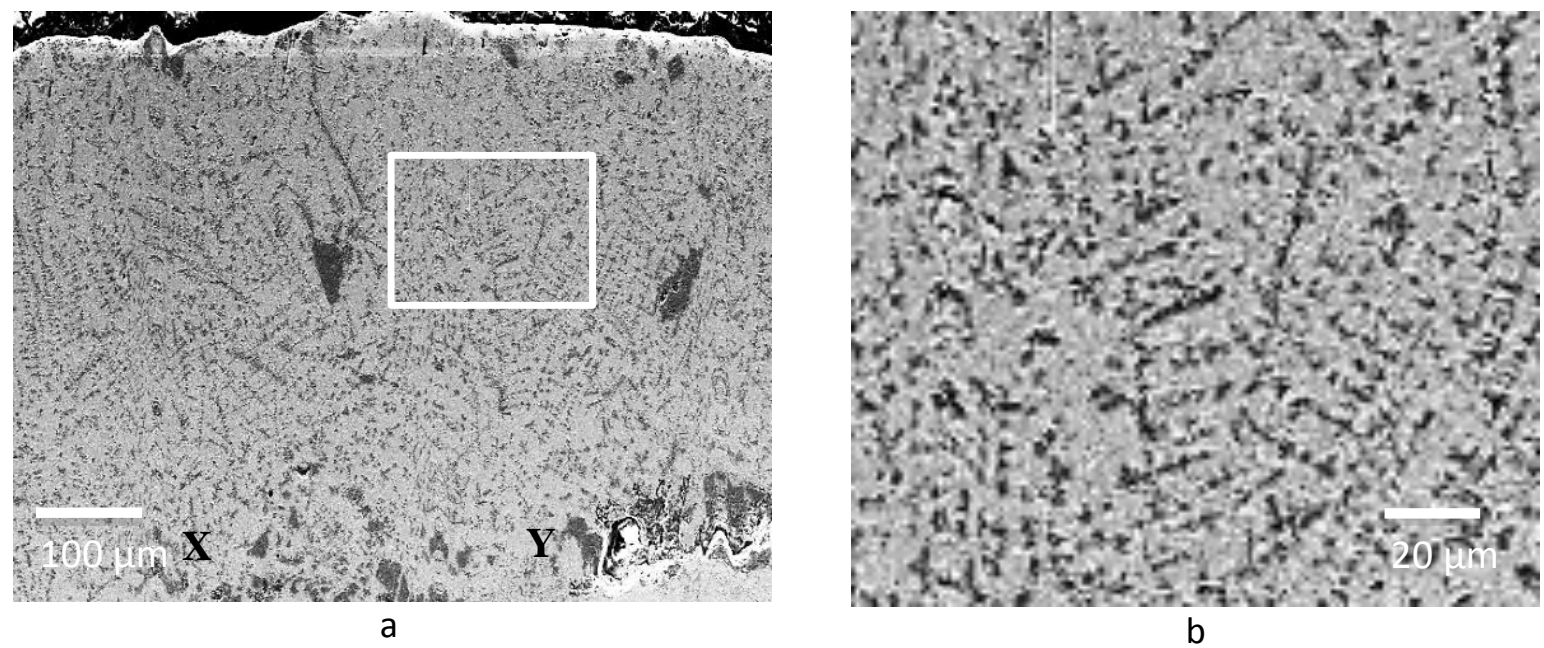

Fig. 6: (a) TiC segregation and agglomeration of particulates in the second half of the track 17 between $\mathrm{X}$ and $\mathrm{Y}$ at the bottom of the melt zone; (b) quasi-dendrites of TiC enlarged from the box in Fig. 6a. 


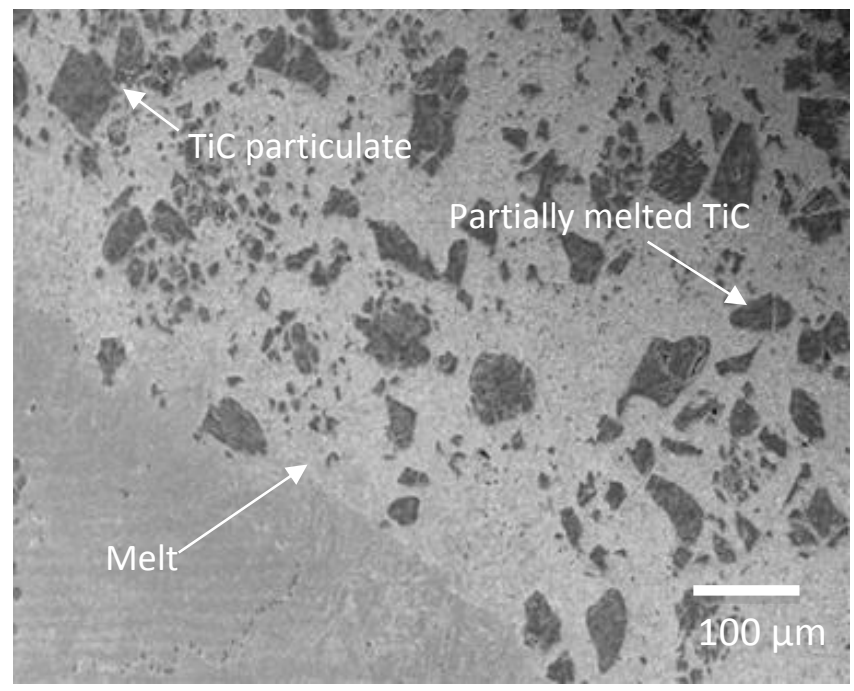

Fig. 7: Sharp edged TiC particulate, with some rounded partially melted TiC and precipitation of TiC in the first track. 


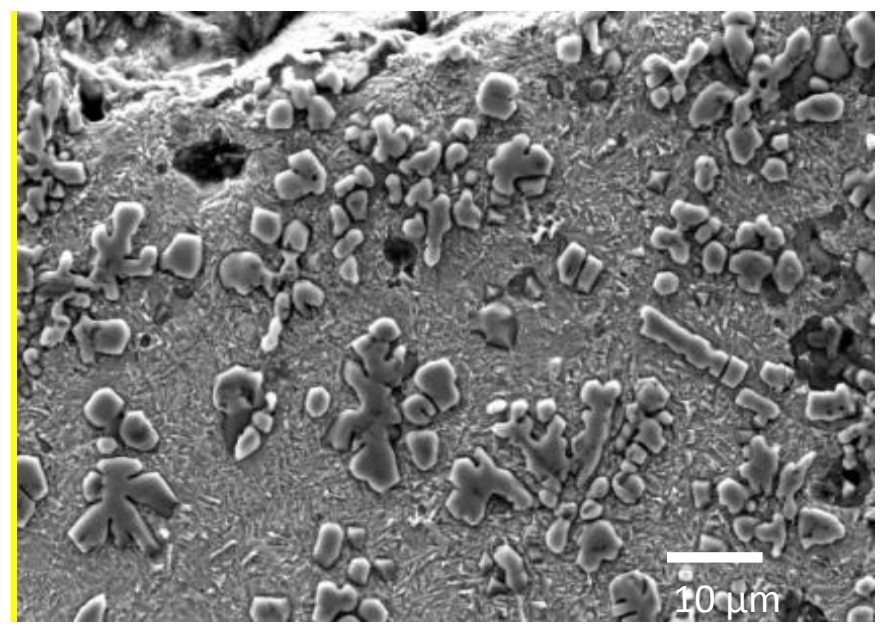

Fig. 8: TiC precipitates near the surface of the second track. 


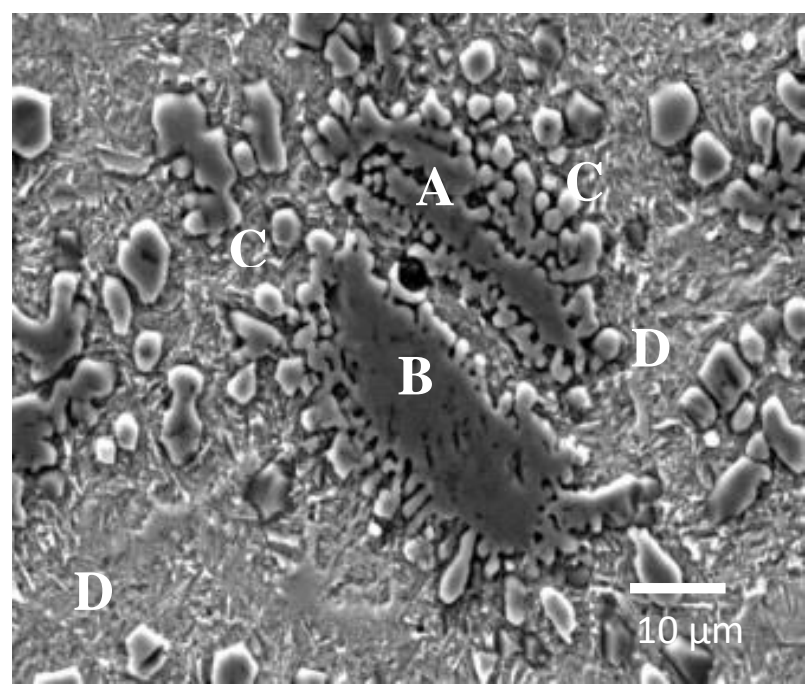

Fig. 9: Partial dissolution of two TiC particulates, A and B, with globular, C, and angular, D, precipitates within the third overlapping track. 


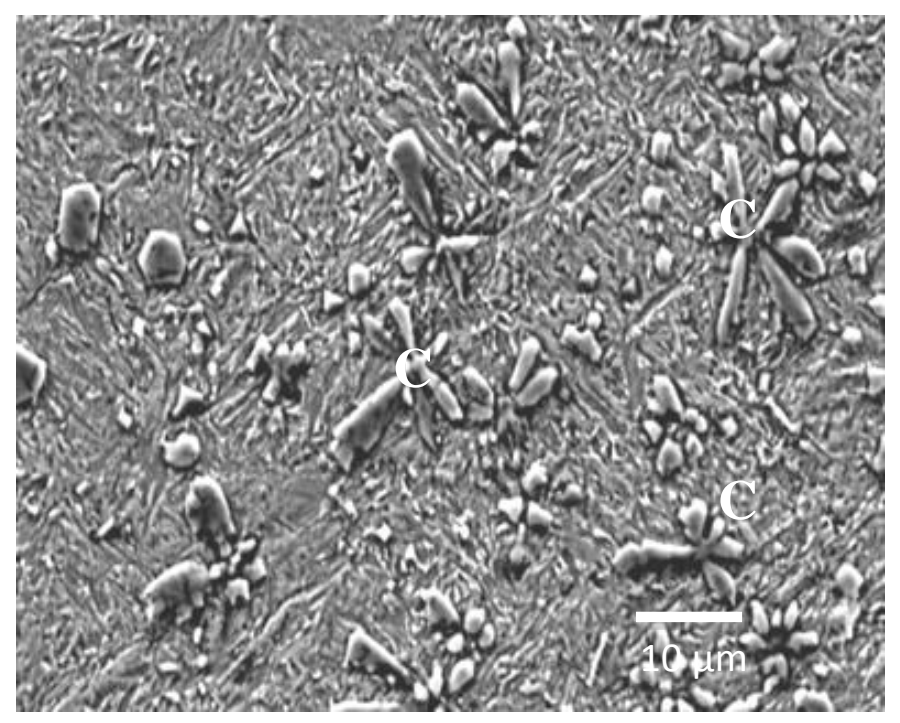

Fig. 10: Flower precipitates are growing at $\mathrm{C}$ in the middle of the ninth melt track. 


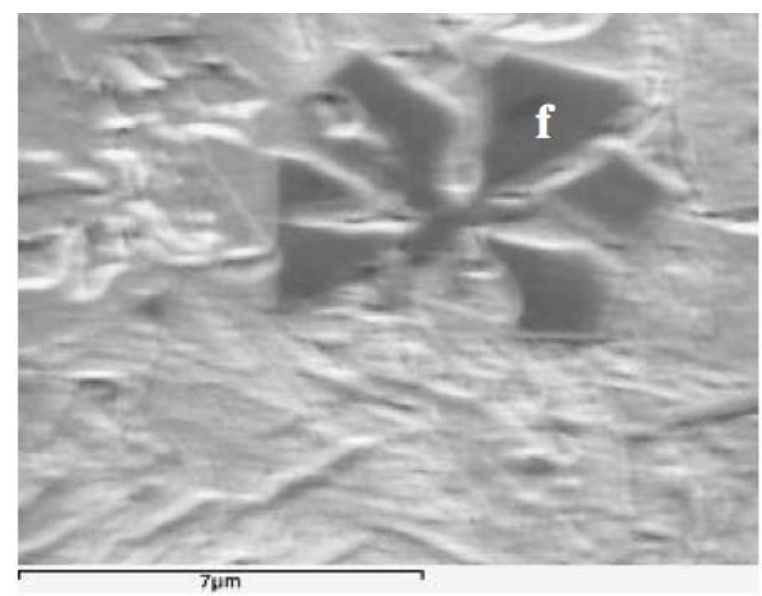

Fig. 11: SEM micrograph showing a well-developed TiC flower precipitate (f). 


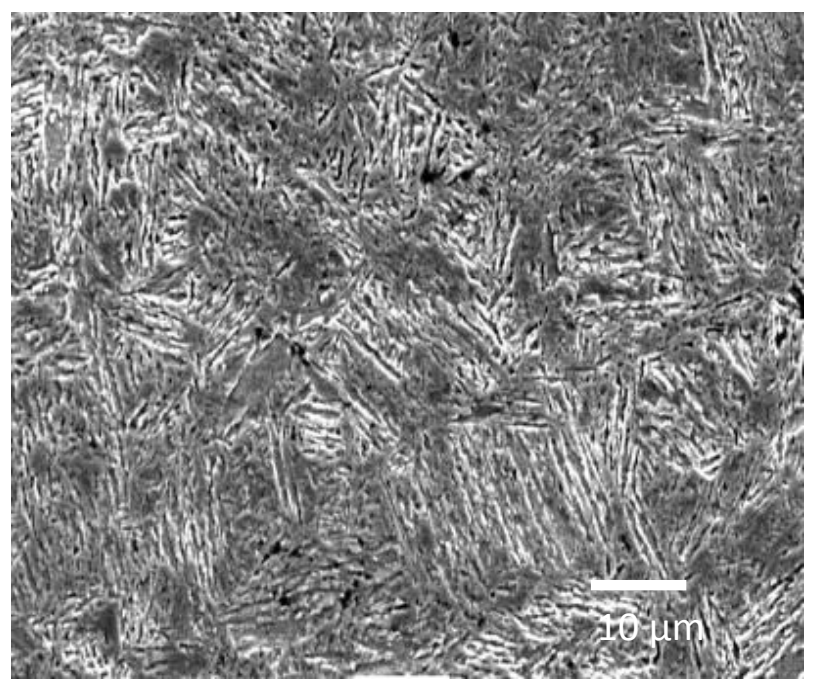

Fig. 12: Martensitic microstructure in the HAZ of the overlapping track. 